\title{
Relationships between Interpersonal Trust and Knowledge Sharing in Workplace: The Mediational Role of Prosocial Motives
}

\author{
Weixu Ding ${ }^{1}$, Eugene Choi $^{1}$, \& Atsushi Aoyama ${ }^{1}$ \\ ${ }^{1}$ Graduate school of Technology Management, Ritsumeikan University, Osaka, Japan \\ Correspondence: Weixu Ding, Graduate School of Technology Management, Ritsumeikan University, 2-150 \\ Iwakura-Cho, Ibaraki, Osaka, 567-8570 Japan.
}

Received: June 23, 2018

doi:10.5539/ibr.v11n8p163

\author{
Accepted: July 23, $2018 \quad$ Online Published: July 25, 2018 \\ URL: https://doi.org/10.5539/ibr.v11n8p163
}

\begin{abstract}
This study is different from the usual cases that testing the intuitive factor as rewarding that affects the employees' knowledge sharing. In this study, the focus shifts to concentrating on the emotional factors such as interpersonal trust and the prosocial motives. Empirical methods are used to test the hypotheses, and the results show that interpersonal trust affects employees' knowledge sharing significantly. Moreover, the prosocial motives have been evidenced that it moderately mediates the relationship between interpersonal trust and knowledge sharing. This study has well evidenced all the hypotheses and gives suggestions for the future research at the end.
\end{abstract}

Keywords: knowledge sharing, interpersonal trust, prosocial motives, empirical method

\section{Introduction}

Knowledge's role as a competitive advantage for corporations' competition has been emphasised (Nonaka and Takeuchi, 1995), and knowledge is broadly recognised as an essential for operating firms successfully in the modern era (Holste \& Fields, 2010). Knowledge sharing is a driving power that urges the knowledge-creating process and directs the intellectual capital performance at a high standard (Liebowitz 2001; Lin, 2008). Fagerberg, Mowery \& Nelson (2005) point out that organisations expect to fortify organisational knowledge assets via transferring employees' knowledge to collective organisational knowledge. For example, some organisations have made huge investments to develop knowledge management systems to encourage the knowledge transfer process, and many corporations develop awarding systems to motivate the individual's sharing aspiration to their co-workers (Connelly \& Zweig, 2015). However, some knowledge is embedded in individuals' brain, and it is acquired from the long-term learning. Haas and Hansen (2007) believe that some knowledge such as personal experience and sharing its progress may need to request their intention. In reality, organisations have been faced with the situation that many of the organisational members have not desired to exchange their knowledge with peers (Denning, 2006; Casimir, Lee \& Loon, 2012). The previous academic contributions reveal the knowledge hiding or withholding phenomenon of employees (Connelly et al., 2012). Accordingly, this study explores the factor that can facilitate employees' intentions of sharing their knowledge, and explain how it can impact individuals' knowledge sharing.

\section{Review and Hypothesis}

Interpersonal trust: The empirical results from the previous academic contribution reveal the knowledge hiding or withholding phenomenon of employees (Connelly et al., 2012), and social scientists believe that trust acts as the catalyst for organisational members' cooperation (Dirks, 1999).

In organisational studies, unlike the institutional trust focusing on the relations between employees and organisations (Anderson \& Schalk, 2010), interpersonal trust as the name implies is based on the trust among individuals (Zaheer, McEvily \& Perrone, 1998). As knowledge sharing is generally recognised as an interaction of the human beings, from previous studies, numbers of scholars support the view that interpersonal trust plays an essential role for intra-organizational knowledge sharing (Hsu \& Chang, 2014).

Mooradian, Renzl \& Matzler(2006) illustrate that interpersonal trust is an expectation of peers' performance that is based on experience (accumulated by observation or interacting process). Previous research shows that organisational members' interpersonal trust has positive relations with their willingness to share knowledge in 
organisations (Weir \& Hutchings, 2005). From the above description, this study summarises that interpersonal trust has been evidenced by previous research that has positive relations with organisational members' intention to share their knowledge. Accordingly, this study proposes the first Hypothesis as follows: H1: Interpersonal trust is positively related to knowledge sharing in the workplace.

Prosocial Motives: The prosocial motive is a concept that is frequently used in psychology, and it is increasingly studied on Organizational citizenship behaviour (OCB) by modern scholars (Rioux \& Penner, 2001; Wah, Menkhoff \& Evers, 2007). Much literature agrees that the OCB is a positive performance in the workplace (Bolino et al., 2015; Organ, Podsakoff \& MacKenzie, 2006), and OCB is an employees' behaviour that has the contribution to maintain the context for tasks (Organ, 1997; Takeuchi, Bolino \& Lin, 2015).

Employees have done more than their duty to help peers voluntarily, take additional responsibility, etc. (Bateman \& Organ, 1983; Bolino et al, 2015; Whiting, Podsakoff \& Pierce, 2008), and OCB is hard to be enforced by others as it is already beyond formal performance requirements (Al-Zu'bi, 2011).

According to the definition by Rioux and Penner (2001), prosocial motives is one of the three motives that are obligated to OCB, and it shows the organisational members' purpose to help and maintain a positive relationship with others (Takeuchi, Bolino \& Lin, 2015).

Unlike the desiring of rewarding for knowledge sharing, people who based on the consideration of personal compatibility may share their knowledge to help others voluntarily for the sociability (Wah et al. 2005; Lin, 2008). In this case, individuals may contribute knowledge to assist others due to this compatibility (Wah, Menkhoff, Loh \& Evers, 2007). Accordingly, this study proposes the second Hypothesis as follows: H2: Prosocial motives are positively related to knowledge sharing in the workplace.

Interpersonal trust and Prosocial Motives: Different from the individualistic motive that expects to maximise individual's interests, the prosocial motive desires to maximise personal outcomes and considering others' benefits as well (De Dreu, Weingart, \& Kwon, 2000; Giebels, de Dreu \& van de Vliert, 2003). Giebels, de Dreu \& van de Vliert(2003) summarise that people with prosocial motives tend to optionally cooperate comparing with egoistic motive, while they would reject cooperation if their partners repetitiously collapse the win-win agreements. Likewise, in the interpersonal relationship, generosity and trust are the preconditions to maintain cooperation (Gardner\& West, 2004; Yost-Dubrow, R., \& Dunham, 2018).

Scholars believe that individuals are more willing to help others whom they have a close personal relationship with (Nonaka \& Takeuchi, 1995; Holste \& Fields, 2010), previous studies also show that trust has strong relations with OCB (Singh \& Srivastava, 2009). In human negotiation, high interpersonal trust contributes to facilitating participants' problem-solving prosocially (Giebels, de Dreu \& van de Vliert, 2003). Accordingly, this study proposes the H3: Interpersonal trust is positively related to prosocial motives.

According to the above description, if assuming that interpersonal trust is positively related to both prosocial motives and knowledge sharing, prosocial motives are also positively associated with knowledge sharing. Depending on the logical relationship, this study proposes the H4: Prosocial motives mediate the relationship between interpersonal trust and knowledge sharing.

\section{Methodology}

Design and Respondents: Quantitative research methods are employed in this research, and a questionnaire is utilised as the tool for data collection. Before distributing to the respondents, we have double-checked and proofread the expression of the questions. After receiving a small scale of people's evaluation of the draft questionnaire, we modified the questions to be more pellucid.

Nearly 300 people from different corporations in China were informed, and they were requested to answer the questionnaire (the participants were selected from our formal co-workers, and graduated school followers).

129 respondents assisted the data collection progress. From the descriptive analysis, 58.91\% of the respondents are female, and $41.09 \%$ of respondents are male. $65.12 \%$ of the respondents' ages are concentrated from 26 to 40 years old, followed by the youth from 18 to 25 years of age with the percentage of $27.13 \%$. From the data set, the position of the respondents is ordinary workers, mid-level managers, and top managers with nearly the percentage of $55.81 \%, 34.88 \%$, and $9.30 \%$ respectively. Most respondents have accepted higher education with $40.31 \%$ acquired a bachelor's degree, and $52.71 \%$ obtained a master's degree.

In Appendix 1, the detail questions of the questionnaire have been illustrated. This study selects the questions from the prior research to measure interpersonal trust (Independent variable). Zaheer, McEvily \& Perrone (1998) have adopted a scale by Rempel \& Holmes (1986) to measure interpersonal trust, and after modification, the 
scale performs well with 0.8799 of Cranach's alpha that largely surpasses the minimum standard with 0.600 of Cranach's alpha (Liao, Fei \& Chen, 2007). Hence, we have adapted this 5-item scale for the second time and include detailed descriptions to ensure the expression is clear and pellucid. Likewise, this study is based on the contribution of Chow \& Chan (2008) and summarises four questions to measure the knowledge sharing (Dependent variable) from the viewpoint of people's intention of knowledge sharing. Further, this study adopts the approach of Grant \& Mayer (2009) to measure the prosocial motive (Mediating Variable) in OCB. A 4-item scale has been used for measurement of prosocial motives.

Reliability and Validity: This research adopts Likert seven scales for the variable measuring: from ' 1 ' to ' 7 ', which equals the agreement level from 'totally disagree' to 'totally agree'. Further, this research adopts 13 items of the objective questions that are prepared to analyse the reliability of the questionnaire; Cranach's alpha value of the total 13 items is 0.902 .

Statistical details of the items are shown as below in Table 1. For quantitative research methods, from experience, if the value of Cranach's Alpha surpasses 0.600 that means the performance of the questionnaire is beyond the ordinary researching level (Liao, Fei \& Chen, 2007).

From Table 1, the minimum value of Cranach's alpha is 0.808 that is much higher than 0.600 . Hence, the questionnaire's reliability is acceptable for further analysis. In this paper, Kaiser-Meyer-Olkin and Bartlett's test is utilised to test whether the data is suitable for factor analysis. The result of KMO value is 0.887 in this research, and 'Bartlett's Test of Sphericity' witnesses significance $(\mathrm{p}<0.001)$.

Table 1. Testing results of Reliability

\begin{tabular}{lll}
\hline Item & Question N & Cranach's Alpha \\
\hline Interpersonal trust & 5 & .808 \\
Prosocial motives & 4 & .899 \\
Knowledge sharing & 4 & .929 \\
\hline
\end{tabular}

Ismail et al. (2010) summarise that, for most of the cases, KMO value is requested no less than 0.600, and 'Bartlett's Test of Sphericity' requires witnessing significance. Hence, the above results mean that the data sets are suitable for factor analysis, and this study uses Exploratory Factor Analysis (EFA) to test the validity.

This study uses the Principal Component Analysis to measure the items: Interpersonal trust, prosocial motives, and Knowledge sharing. In table 2, the results show that there are three components, and the loading value that surpasses 0.5 has been displayed.

Accordingly, this study summarises as follows: The factor load of all the items used for measuring knowledge sharing is satisfactory; the factor load of all the items used for measuring prosocial motives is satisfactory; Four-fifth of the items' factor load that is used for measuring interpersonal trust is satisfactory. After testing the validity of this questionnaire, this study starts the following analysing. According to the methods by Casimir, \& Loon (2012), this study uses the mean value of the satisfactory items of each component that has been used to scores the three variables as independent, dependent and mediating variables.

From Table 3, the correlations between independent, dependent and mediating variables perform significantly. The results show that interpersonal trust has positive correlations with both knowledge sharing $(r=.586 ; p<0.01)$ and prosocial motives $(\mathrm{r}=.265 ; \mathrm{p}<0.01)$. Additionally, the prosocial motive is significantly related to knowledge sharing $(\mathrm{r}=.517 ; \mathrm{p}<0.01)$.

Table 2. Rotated Component Matrix

\begin{tabular}{lccc}
\hline Items & & Component & 3 \\
KS4 & 1 & 2 & \\
KS3 & .866 & & \\
KS2 & .862 & & \\
KS1 & .855 & .914 & \\
PM2 & .739 & .858 & .810 \\
PM1 & & .827 & .739 \\
PM4 & & .761 & .725 \\
PM3 & & & .649 \\
IT4 & & & \\
IT5 & & & \\
IT3 & & & \\
IT2 & & & \\
\hline
\end{tabular}

Extraction Method: Principal Component Analysis 
Rotation method: Varimax with Kaiser Normalization

a. Rotation converged in 5 iterations. KS=Knowledge sharing; PM=Prosocial motives; IT=Interpersonal Trust.

Table 3. Descriptive analysis and Correlations

\begin{tabular}{|c|c|c|c|c|c|c|}
\hline Variables & Mean & S. D. & 1 & 2 & 3 & 4 \\
\hline 1.Individual status & 1.53 & .662 & & & & \\
\hline 2.Workers' educational level & 2.48 & .626 & -.060 & & & \\
\hline 3. Interpersonal trust & 4.90 & 1.057 & .120 & $-.204 *$ & & \\
\hline 4.Prosocial Movies & 5.63 & 1.029 & $.273 * *$ & -.058 & $.265^{* *}$ & \\
\hline $\begin{array}{c}\text { 5.Knowledge sharing } \\
\text { Valid } \mathrm{N}=129\end{array}$ & 5.48 & 1.130 & $.311 * *$ & $-.190 *$ & $.586^{* *}$ & $.517 * *$ \\
\hline
\end{tabular}

Notes. Gender: '1'= 'male ';'2'='female'

Individual's educational level: ' 1 '=Bachelor',' $2=$ Master ' $3=$ 'Doctor.'

Individual's status: '1'='Ordinary'; '2'= 'medium '; '3'='senior manager'

**. $\mathrm{P}<0.01$ (2-tailed). *. $\mathrm{P}<0.05$ (2-tailed)

\section{Hypothesis Testing}

From the information in Table 4, Model $1\left(\mathrm{R}^{2}=.344, \mathrm{p}<0.001\right)$ shows that interpersonal trust has a significant effect on knowledge sharing with $\beta=.594, p<0.001$. Hence, these results support Hypothesis 1 : Interpersonal trust has a positive role in knowledge sharing. This result means people have higher interpersonal trust with their peers, their aspiration on knowledge sharing would be stronger.

Further, Model 2( $\left.\mathrm{R}^{2}=.268, \mathrm{p}<0.001\right)$ shows the positive effect of prosocial motives on knowledge sharing. The analysing results also evidence that prosocial motives have a significant impact on knowledge sharing with $\beta=$. $568, \mathrm{p}<0.001$. Hence, this result supports Hypothesis 2 successfully and illustrates that stronger prosocial motives would promote organisational members' knowledge sharing. Model $4\left(\mathrm{R}^{2}=.070, \mathrm{p}<0.01\right)$, and additionally, illustrates the relations between interpersonal trust and prosocial motives, and the analysing results show that interpersonal trust has significant effects on prosocial motives of $\beta=.244, p<0.01$. Hence, this result fully supported the Hypothesis 3. This result symbolises that Organisations can promote people's prosocial motives via strengthening the interpersonal trust among peers.

Accordingly, the above descriptions illustrate the correlation of interpersonal trust, prosocial motives, and knowledge sharing. The followings would be the test of prosocial motives' mediating role in the relationship between interpersonal trust and knowledge sharing.

This research adopts the classical approaches by Baron \& Kenny (1986) to examine the mediating effects, and the conditions are summarised as below: 1. Independent variables need to affect dependent variables significantly; 2. Independent variables need to affect the mediator significantly; 3. Mediate variable needs to affect a dependent variable significantly; 4 . Whether the independent variable's significance changes when including mediating variable into the original model that examines the relationship between the independent variable and dependent variable.

Table 4. Regression analysis

\begin{tabular}{llllll}
\hline Variables & & \multicolumn{2}{l}{ Knowledge Sharing } & \multicolumn{2}{l}{ Prosocial motives } \\
\hline & & Model 1 & Model 2 & Model 3 & Model 4 \\
Constant & & $2.687 * *$ & $2.287 * * *$ & .775 & $4.475 * * *$ \\
Explanatory & Interpersonal trust & $.594 * *$ & & $.489 * * *$ & $.244 * *$ \\
& Prosocial motive & & $.568 * * *$ & $.427 * * *$ & \\
Model Statistic & $\mathrm{R}^{2}$ & .344 & .268 & .485 & .070 \\
& $\mathrm{~F}$ & $66.556 * * *$ & $46.437 * * *$ & $59.292 * * *$ & $9.592 * *$ \\
\hline
\end{tabular}

***.P $<0.001 ; * * . \mathrm{P}<0.01 ; * . \mathrm{P}<0.05$;

According to the regression analysis results, the results support Hypothesis 1, and Model 1 satisfies the condition one by the independent variable's effects on the dependent variable is significant. Model 4, additionally, illustrates the relations between interpersonal trust and prosocial motives, and independent variable significantly affects the mediating variable. Model 1 evidences that prosocial motives have a significant effect on individuals' knowledge sharing, and this satisfies condition 3: Mediator has a significant effect on the dependent variable. After satisfying the above three conditions, we begin to include the mediator into the interaction model of independent and dependent variables to examine whether it satisfies the last condition to prove the existence of the mediating effect. 
Model $3\left(R^{2}=.485, p<0.001\right)$ is created based on Model $1\left(R^{2}=.344, p<0.001\right)$ and includes the mediator into the model. Comparing Model 3 and Model 1, it is not tough to find that the $\beta$ value of 'interpersonal trust' reduces from 0.594 to 0.489 , and the significant level still witnesses significance. The examining result satisfies the experimental requirements as if the independent variable's affecting significance vanishes that means the independent variable is wholly mediated, and the other situation may show that it is partly mediating effect (Sarkis, Gonzalez-Torre \& Adenso-Diaz, 2010).

Hence, analysing results show that prosocial motives partly mediate interpersonal trust's effect on knowledge sharing. Although $\mathrm{H} 4$ has been supported, the results show that the channels linking the interpersonal trust and knowledge sharing are not limited to prosocial motives. Therefore, other mediators may need to be explored in future studies.

\section{Discussion and Conclusion}

This paper has already proven the Hypothesis from 1 to 4 that are fully supported by the analysing results. This research shows that the interpersonal trust has a positive effect on employees' knowledge sharing. Accordingly, people are more willing to share with persons of higher-level interpersonal trust with them. Further, people's prosocial motives also contribute to their knowledge sharing intention. That means people's motives in helping others facilitate their knowledge sharing to be compatible. According to the research result, people's prosocial motive is also based on their interpersonal trust with their peers.

However, there are several limitations of this research which also need to be pointed out. The questionnaire has been sent by experience, and the survey is designed by self-evaluation. Hence, respondents' higher evaluation of themselves may cause the statistical deviation.

Further, interpersonal trust has been emphasised and evidenced to affect the process of knowledge sharing positively. That does not mean that only interpersonal trust has this unique effect. Hence, in future studies, more research could focus on this direction to explore the factor that can boost employees' knowledge sharing. From the research results, the relationship between interpersonal trust and knowledge sharing in the workplace has been proved to be partly mediated by prosocial motives. Hence, this result means there are not just prosocial motives that have the bridge effects.

Accordingly, in the future research, some other factors are suggested to be explored. Furthermore, empirical methods have been used. Researchers believe that a single research approach might limit the perspective (e.g. Carr, 1994; Duffy, 1987). Hence, the diversity of research methods should be suggested for the future studies.

\section{References}

Al-Zu'bi, H. A. (2011). Organizational citizenship behavior and impacts on knowledge sharing: An empirical study. International Business Research, 4(3), 221. https://doi.org/10.5539/ibr.v4n3p221

Anderson, N., \& Schalk, R. (2010). The psychological contract in retrospect and prospect. Journal of Organizational Behavior, 19(S1), 637-647. https://doi.org/10.1002/(SICI)1099-1379(1998)19:1+<637::AID-JOB986>3.0.CO;2-H

Bateman, T. S., \& Organ, D. W. (1983). Job satisfaction and the good soldier: The relationship between affect and employee "citizenship". Academy of Management Journal. 1983 Dec 1; 26(4), 587-595.

Bolino, M. C., Hsiung, H. H., Harvey, J., \& LePine, J. A. (2015). “Well, I'm tired of try in’!” Organizational citizenship behavior and citizenship fatigue. Journal of Applied Psychology, 100(1), 56. https://doi.org/10.1037/a0037583

Carr, L. T. (1994). The strengths and weaknesses of quantitative and qualitative research: what method for nursing? Journal of advanced nursing, 20(4), 716-721. https://doi.org/10.1046/j.1365-2648.1994.20040716.x

Casimir, G., Lee, K., \& Loon, M. (2012). Knowledge sharing: influences of trust, commitment and cost. Journal of Knowledge Management, 16(5), 740-753(14). https://doi.org/10.1108/13673271211262781

Chow, W. S., \& Chan, L. S. (2008). Social network, social trust and shared goals in organisational knowledge sharing. Information \& Management, 45(7), 458-465. https://doi.org/10.1016/j.im.2008.06.007

Connelly, C. E., \& Zweig, D. (2015). How perpetrators and targets construe knowledge hiding in organisations. European Journal of Work and Organizational Psychology, 24(3), 479-489. https://doi.org/10.1080/1359432X.2014.931325

Connelly, C. E., Zweig, D., Webster, J., \& Trougakos, J. P. (2012). Knowledge hiding in organisations. Journal 
of Organizational Behavior, 33(1), 64-88. https://doi.org/10.1002/job.737

De Dreu, C. K., Weingart, L. R., \& Kwon, S. (2000). Influence of social motives on integrative negotiation: a meta-analytic review and test of two theories. Journal of Personality and Social Psychology, 78(5), 889. https://doi.org/10.1037/0022-3514.78.5.889

Denning, S. (2006). Ten steps to get more business value from knowledge management. Strategy \& Leadership, 34(6), 11-16. https://doi.org/10.1108/10878570610711224

Dirks, K. T. (1999). The effects of interpersonal trust on workgroup performance. Journal of applied psychology, 84(3), 445. https://doi.org/10.1037/0021-9010.84.3.445

Duffy, M. E. (1987). Methodological triangulation: a vehicle for merging quantitative and qualitative research methods. Journal of Nursing Scholarship, 19(3), 130-133. https://doi.org/10.1111/j.1547-5069.1987.tb00609.x

Fagerberg, J., Mowery, D. C., \& Nelson, R. R. (Eds.). (2005). The Oxford handbook of innovation. Oxford university press.

Gardner, A., \& West, S. A. (2004). Cooperation and punishment, especially in humans. The American Naturalist, 164(6), 753-764. https://doi.org/10.1086/425623

Giebels, E., de Dreu, C. K., \& van de Vliert, E. (2003). No way out or swallow the bait of two-sided exit options in negotiation: The influence of social motives and interpersonal trust. Group processes \& intergroup relations, 6(4), 369-386. https://doi.org/10.1177/13684302030064004

Grant, A. M., \& Mayer, D. M. (2009). Good soldiers and good actors: prosocial and impression management motives as interactive predictors of affiliative citizenship behaviours. Journal of Applied Psychology, 94(4), 900. https://doi.org/10.1037/a0013770

Haas, M. R., \& Hansen, M. T. (2007). Different knowledge, different benefits: toward a productivity perspective on knowledge sharing in organisations.

Holste, J. S., \& Fields, D. (2010). Trust and tacit knowledge sharing and use. Journal of Knowledge Management, 14(1), 128-140. https://doi.org/10.1108/13673271011015615

Hsu, M. H., \& Chang, C. M. (2014). Examining interpersonal trust as a facilitator and uncertainty as an inhibitor of intra - organisational knowledge sharing. Information Systems Journal, 24(2), 119-142. https://doi.org/10.1111/isj.12000

Ismail, A., Mohamad, M. H., Mohamed, H. A. B., Rafiuddin, N. M., \& Zhen, K. W. P. (2010). Transformational and Transactional Leadership Styles as a Predictor of Individual Outcomes. Theoretical \& Applied Economics, 17(6).

Liao, S. H., Fei, W. C., \& Chen, C. C. (2007). Knowledge sharing, absorptive capacity, and innovation capability: an empirical study of Taiwan's knowledge-intensive industries. Journal of information science, 33(3), 340-359. https://doi.org/10.1177/0165551506070739

Liebowitz J. (2001). Knowledge management and its link to artificial intelligence. Expert systems with applications, 2001 Jan 1; 20(1), 1-6. https://doi.org/10.1016/S0957-4174(00)00044-0

Lin, C. P. (2008). Clarifying the relationship between organisational citizenship behaviours, gender, and knowledge sharing in workplace organisations in Taiwan. Journal of Business and Psychology, 22(3), 241-250. https://doi.org/10.1007/s10869-008-9067-z

Mooradian, T., Renzl, B., \& Matzler, K. (2006). Who trusts? Personality, trust and knowledge sharing. Management Learning, 37(4), 523-540. https://doi.org/10.1177/1350507606073424

Nonaka, I., \& Takeuchi, H. (1995). Knowledge-creating company. Bloomsbury Business Library - Management Library.

Organ, D. W. (1997). Organizational citizenship behaviour: It's construct clean-up time. Human Performance, 10, 85-97. https://doi.org/10.1207/s15327043hup1002_2

Organ, D. W., Podsakoff, P. M., \& MacKenzie, S. B. (2006). Organizational citizenship behaviour: Its nature, antecedents, and consequences. Thousand Oaks, CA: Sage.

Rempel, J. K., \& Holmes, J. G. (1986). How do I trust thee? Psychology Today, 20(2), 28-34.

Rioux, S. M., \& Penner, L. A. (2001). The causes of organisational citizenship behaviour: a motivational analysis. 
Journal of Applied Psychology, 2001 Dec; 86(6), 1306. https://doi.org/10.1037/0021-9010.86.6.1306

Sarkis, J., Gonzalez-Torre, P., \& Adenso-Diaz, B. (2010). Stakeholder pressure and the adoption of environmental practices: The mediating effect of training. Journal of Operations Management, 28(2), 163-176. https://doi.org/10.1016/j.jom.2009.10.001

Takeuchi, R., Bolino, M. C., \& Lin, C. C. (2015). Too many motives? The interactive effects of multiple motives on organisational citizenship behaviour. Journal of Applied Psychology, 100(4), 1239. https://doi.org/10.1037/ap10000001

Wah, C. Y., Loh, B., Menkhoff, T., \& Evers, H. D. (2005, January). Theorizing, measuring, and predicting knowledge sharing behaviour in organizations-a social capital approach. In System Sciences, 2005. HICSS'05. Proceedings of the 38th Annual Hawaii International Conference on (pp. 252b-252b). IEEE.

Wah, C. Y., Menkhoff, T., Loh, B., \& Evers, H. D. (2007). Social capital and knowledge sharing in knowledge-based organisations: An empirical study. International Journal of Knowledge Management (IJKM), 3(1), 29-48. https://doi.org/10.4018/jkm.2007010103

Weir, D., \& Hutchings, K. (2005). Cultural embeddedness and contextual constraints: knowledge sharing in Chinese and Arab cultures. Knowledge \& Process Management, 12(2), 89-98. https://doi.org/10.1002/kpm.222

Whiting, S. W., Podsakoff, P. M., \& Pierce, J. R. (2008). Effects of task performance, helping, voice, and organisational loyalty on performance appraisal ratings. Journal of Applied Psychology, 93(1), 125. https://doi.org/10.1037/0021-9010.93.1.125

Yost-Dubrow, R., \& Dunham, Y. (2018). Evidence for a relationship between trait gratitude and prosocial behaviour. Cognition and Emotion, 32(2), 397-403. https://doi.org/10.1080/02699931.2017.1289153

Zaheer, A., McEvily, B., \& Perrone, V. (1998). Does trust matter? Exploring the effects of inter-organisational and interpersonal trust on performance. Organization Science, 9(2), 141-159. https://doi.org/10.1287/orsc.9.2.141 


\section{Appendix 1}

Notes: Likert 7 scales are used: ' 1 ' to ' 7 ' equals the agreement level 'totally disagree' to 'totally agree'. Respondents are requested to answer according to their situation to score the agreement level of the description below.

Knowledge sharing (KS) adapts from Chow \& Chan (2008)

KS 1: I am willing to share my work report, organisational documents with colleagues more diligently in $m y$ future work.

KS 2: $I$ am willing to share relevant work guides, models, and methods with $m y$ colleagues in the future.

KS 3: $I$ am willing to share $m y$ accumulated experience and theoretical knowledge with $m y$ colleagues.

KS 4: I am willing to share $m y$ knowledge gained via learning and training with $m y$ colleagues.

Prosocial motives (PM) adapts from Grant \& Mayer (2009)

PM 1: $I$ hope $m y$ action at work has the positive effect on others.

PM 2: I hope $I$ can help others via $m y$ works.

PM 3: $I$ think if $I$ have the ability to help others that will make me more excellent at work.

PM 4: $I$ think if $I$ have the ability to help others that will make $m y$ peers have a good impression.

Interpersonal trust (IT) adapts from Zaheer, McEvily \& Perrone (1998)

IT 1: $I$ have been consulting the people $I$ work with.

IT 2: $I$ can predict accurately of the action of the people $I$ contact.

IT 3: $I$ think most of the people $I$ interact with are trustworthy.

IT 4: $I$ am sure the people $I$ meet will consider $m y$ interests.

IT 5: $I$ will feel frustrated if $I$ cannot predict the behaviour of people $I$ interact with well.

\section{(The questionnaire is written in Chinese, and the above is the English translation)}

\section{Copyrights}

Copyright for this article is retained by the author(s), with first publication rights granted to the journal.

This is an open-access article distributed under the terms and conditions of the Creative Commons Attribution license (http://creativecommons.org/licenses/by/4.0/). 